\title{
Preoperative Risk Factors for Conversion of Laparoscopic Cholecystectomy to Open Surgery - A Systematic Review and Meta-Analysis of Observational Studies
}

\author{
Josephine Philip Rothman ${ }^{\text {a Jakob Burcharth }}{ }^{a}$ Hans-Christian Pommergaard ${ }^{a}$ \\ Søren Viereck ${ }^{b}$ Jacob Rosenberg ${ }^{a}$ \\ ${ }^{a}$ Department of Surgery, Center for Perioperative Optimization, Herlev Hospital, and ${ }^{\text {b } E m e r g e n c y ~ M e d i c a l ~ S e r v i c e ~}$ \\ Copenhagen, University of Copenhagen, Copenhagen, Denmark
}

\section{Key Words}

Cholecystectomy · Risk factors · Conversion · Preoperative ·

Systematic review

\begin{abstract}
Background: Preoperative risk factors for the conversion of laparoscopic cholecystectomy to open surgery have been identified, but never been explored systematically. Our objective was to systematically present the evidence of preoperative risk factors for conversion of laparoscopic cholecystectomy to open surgery. Methods: PubMed and Embase were searched systematically in March 2014. Observational studies evaluating preoperative risk factors for conversion of laparoscopic cholecystectomy to open surgery in patients with gallstone disease were included. The outcome variables extracted were patient demographics, medical history, severity of gallstone disease, and preoperative laboratory values. Results: A total of 1,393 studies were screened for eligibility. We found 32 studies, including 460,995 patients operated with laparoscopic cholecystectomy, eligible for the systematic review. Of these, 10 studies were suitable for 7 meta-analyses on age, gender, body mass index, previous abdominal surgery, severity of disease, white blood cell
\end{abstract}

count, and gallbladder wall thickness. Conclusions: A gallbladder wall thicker than 4-5 mm, a contracted gallbladder, age above 60 or 65 , male gender, and acute cholecystitis were risk factors for the conversion of laparoscopic cholecystectomy to open surgery. Furthermore, there was no association between diabetes mellitus or white blood cell count and conversion to open surgery.

(c) 2016 S. Karger AG, Basel

\section{Introduction}

Laparoscopic cholecystectomy is a common operation in the Western world $[1,2]$, usually performed as elective surgery with low mortality and morbidity [3]. It has been reported that $1.8-27.7 \%$ of laparoscopic cholecystectomies are converted to open surgery during the operation $[4,5]$. Converted cases are associated with increased numbers of infectious and other postoperative complications [6-10], increased risk of additional procedures, and a higher 30-day readmission rate [11]. Overall, conversion from laparoscopic to open operation results in longer postoperative stays and morbidity and mortality rates are higher in this group of patients $[11,12]$.

\section{KARGER}

E-Mail karger@karger.com

www.karger.com/dsu
(C) 2016 S. Karger AG, Basel

0253-4886/16/0335-0414\$39.50/0
Josephine Philip Rothman, BSc (Med)

Department of Surgery

University of Copenhagen, Niels Hemmingsens Gade 32A, 3th

DK-1153 Copenhagen (Denmark)

E-Mail josephineprothman@gmail.com 
Identifying preoperative patient-related variables, predicting the need for conversion of laparoscopic cholecystectomy to open surgery may help to identify high-risk patients and redefine the surgical strategy in this group, for example, ensuring sufficient available expertise for complicated cases. The purpose of this systematic review and meta-analysis was to investigate if certain preoperative patient-related characteristics increased the risk of conversion of laparoscopic cholecystectomy to open surgery, in patients undergoing cholecystectomy due to gallstone disease.

\section{Method}

This systematic review and meta-analysis were conducted according to Preferred Reporting Items for Systematic Reviews and Meta-Analysis (PRISMA) [13]. Prior to data extraction and analysis, the review was registered at the International Prospective Register of Systematic Reviews [14] with the registration number CRD42014009222. The research question that drove the review was: which preoperative patient-related characteristic affects the risk of converting laparoscopic cholecystectomies to open surgery in patients with gallstone disease?

\section{Eligibility Criteria}

The literature search strategy was created on the basis of the following eligibility criteria: we included English and Scandinavian language articles available in full-text. Inclusion criteria for the systematic review were prospectively collected prognostic studies reporting preoperative risk factors for standard 4-port laparoscopic cholecystectomy. The indication for surgery had to be gallstone disease. Articles were excluded if adjusted analyses (i.e. multivariate logistic regression) were not reported. No restrictions regarding the type and method of adjusted analyses were applied. Only studies reporting ORs with 95\% CI for all significant, as well as, insignificant risk factors in the multivariate analysis were eligible for the meta-analyses. No restrictions were made regarding the time of publication.

\section{Search Strategy}

PubMed and Embase were systematically searched for relevant articles on March 24, 2014. The search strategy was created with help from a librarian and conducted by the first author (table 1).

The search strategy was modified to fit Embase. Duplicates occurring in both databases were removed, after which the title and abstract of the records were independently screened by 2 authors (J.P.R. and S.V.). To measure the degree of agreement between the two authors in the screening process, a kappa value was calculated [15]. According to the Cochrane Handbook [15] kappa values between 0.40 and 0.59 are categorized as fair agreement, values between 0.60 and 0.74 are categorized as good agreement and values over 0.75 are categorized as excellent agreement. If title or abstract met the eligibility criteria, full texts of the articles were obtained. Any discrepancies were solved by discussion. One additional study [16] was identified through snowball search [17].

Preoperative Risk Factor for Conversion of Cholecystectomy
Table 1. Search strategy for PubMed

(((('Risk Factors'[Mesh] OR 'risk factor*’ OR * risk* OR probability OR epidemiolog*)) AND ('Cholecystectomy, Laparoscopic'[Mesh] OR 'laparoscopic cholecystectomy' OR laparoscop* OR celioscop* OR coelioscop* OR abdominoscop* OR cholecystecto* OR colecystecto*)) AND (biliary OR 'biliary Tract Diseases'[Mesh] OR 'Biliary Tract'[Mesh] OR gall-bladder OR 'gall bladder' OR 'gallbladder'[Mesh] OR ‘Gallbladder Diseases'[Mesh] OR gallbladder OR cholecyst*)) AND ('Conversion to Open Surgery'[Mesh] OR 'conversion to open surgery' OR conversion* OR 'postoperative complication*’)

\section{Data Collection and Data Items}

The studies included in the systematic review were analyzed to identify all reported preoperative risk factors. The identified variables were then extracted from the included studies. The collected study data were number of participants, year of publication, and statistical methods. The extracted outcome variables (preoperative risk factors for conversion of laparoscopic cholecystectomy to open surgery) were:

- Patient demographics (age (the studies used either 60 or 65 years as their cut-off value), gender, weight/body mass index (BMI; cut-off 27.5-35), body temperature, American Society of Anesthesiologist (ASA)-score),

- Medical history (diabetes mellitus, previous abdominal surgery),

- Gallstone disease (acute or chronic cholecystitis, wall thickness of gallbladder, pericholecystic fluid on preoperative ultrasound),

- Preoperative laboratory values (aspartate aminotransferase, alanine aminotransferase, alkaline phosphatase, bilirubin, C-reactive protein)

\section{Statistical Analysis}

The study data, above-mentioned outcome variables, and OR with $95 \%$ CI for all preoperative risk factors with uni- and multivariate analyses were extracted from the included studies. If the OR for a univariate analysis was not specified, it was calculated using the frequencies whenever possible. Only studies specifying significant results, as well as, non-significant results in the multivariate analysis were included in the meta-analyses. Studies not reporting non-significant results in the multivariate analysis were excluded from the meta-analysis and only reported narratively. Studies reporting continuous variables instead of using a cut-off value when generating the multivariate analysis were excluded from the meta-analysis.

For generating the meta-analyses, we used the software Review Manager [18]. The 'Generic Inverse Variance' mode was used, in which the OR for the specified outcome was entered for each study. The multivariate OR was used whenever available. For studies reporting variables as non-significant risk factors, the univariate OR was used in cases where the multivariate OR was not available.

The degree of heterogeneity across studies was expressed as $\mathrm{I}^{2}$. We classified $\mathrm{I}^{2}$ of 25,50 , and $75 \%$ as low, medium and high heterogeneity, respectively [19]. If heterogeneity across studies was high $\left(\mathrm{I}^{2}>75 \%\right)$, the Forest plots were shown to illustrate the effect of the risk factor; however, the pooled effect size was left out due to uncertainty of the true estimate. If heterogeneity was above $0 \%$, 
the random effect model for meta-analysis was used to take the heterogeneity across studies into account. Otherwise, the fixed effect model was used.

Risk of Bias within Studies and Quality Assessment

We used the Newcastle-Ottawa Scale (NOS) for evaluating bias in comparative and non-comparative observational studies [20] as recommended by the Cochrane Collaboration [21], to assess the risk of bias within studies. The NOS scale rates the studies on selection, comparability, and outcome with 0-9 stars. A score of 0 stars indicates highest possible degree of bias, whereas 9 stars indicate the lowest degree of bias. The median and range of NOS values are presented for all included studies as well as for the studies included in each of the meta-analyses.

The Cochrane recommended GRADE tool was used to evaluate the quality of evidence on outcome level (risk factors) for the meta-analyses. The software used was GRADEpro, version 3.5 for Windows [22]. Based on the overall assessment, GRADE rates the quality of evidence as very low, low, moderate, or high. Meta-analyses of randomized controlled trials always start out as a high quality of evidence, where observational studies start out as low quality of evidence, and may thereafter be up- or downgraded. Outcomes may be downgraded in case of high risk of bias across studies (median NOS $<7$ ), high degree of inconsistency $\left(\mathrm{I}^{2}>75 \%\right)$, indirectness, imprecision, or risk of publication bias. Outcomes may be upgraded as a consequence of large outcome-effect or possible confounding underestimating the effect [23].

\section{Results}

This systematic review included 32 prospective observational and database studies $[4,7-11,16,24-48]$ including 460,995 patients. Information about the individual studies are available online as supplementary material. Multiple databases were basis for more than one study, that is, duplicate publications in separate papers. To reduce publication bias, we excluded the studies with the lowest NOS score or the fewest included patients. This resulted in exclusion of 4 duplicate studies [5, 49-51]. A total of 10 studies were eligible for meta-analysis ( $n=25,778$; fig. 1 ).

The degree of agreement between the 2 authors assessing the study eligibility had a kappa value of 0.68 , corresponding to good agreement [15].

All the included studies were evaluated for bias using NOS. The median score for all studies was 8 (range 5-9) (table 2). The NOS score was typically reduced, because many studies did not describe follow-up (outcome).

\section{Risk of Bias Across Studies}

Quality of evidence in the meta-analyses all started out as low quality due to the observational nature of the included studies. One of the outcomes was upgraded as a result of strong association between risk factors and conversion

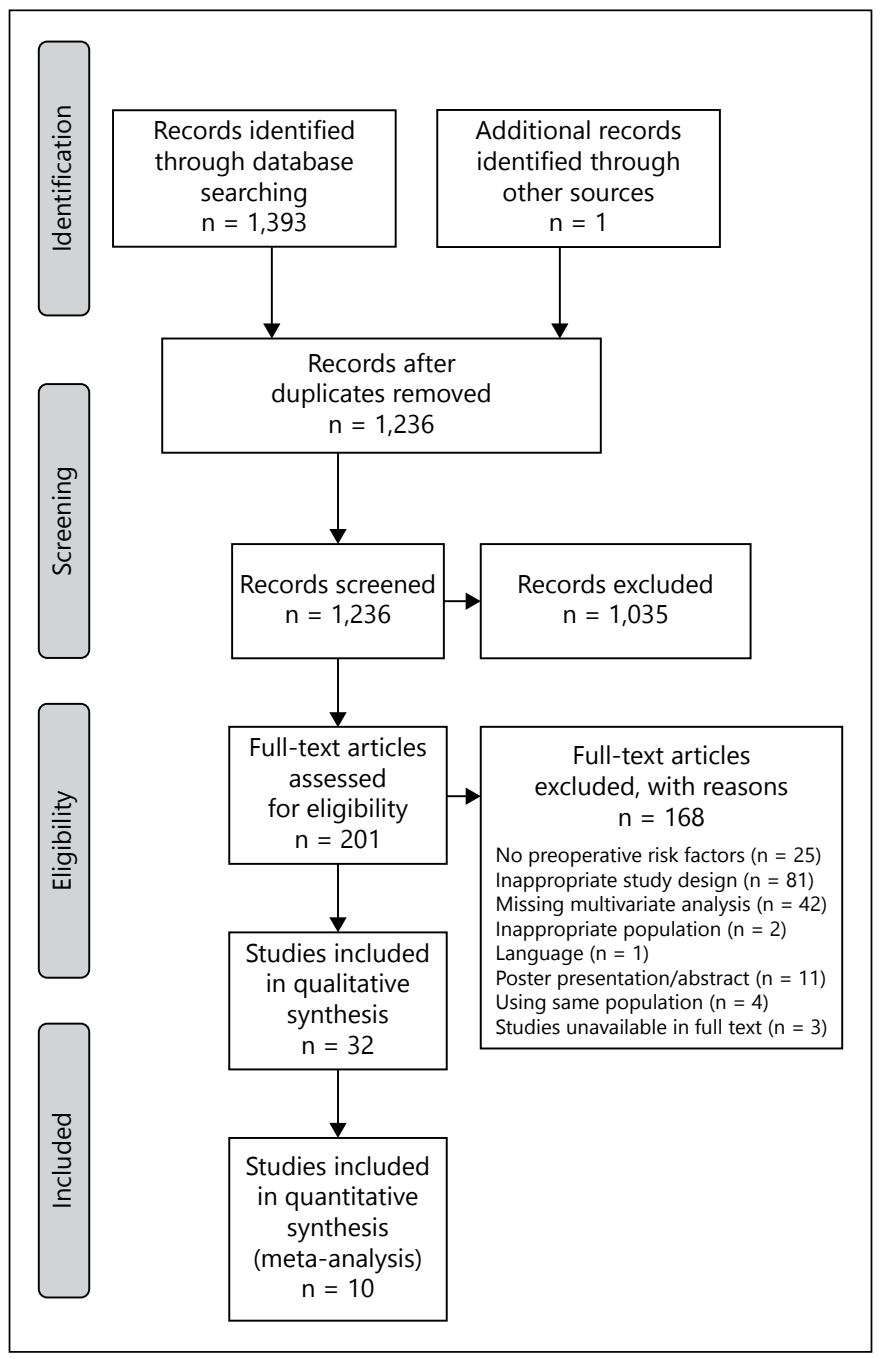

Fig. 1. PRISMA [13] flow diagram.

to open surgery (gallbladder thickness). Three outcomes were downgraded as a result of high heterogeneity (weight, previous abdominal surgery, acute cholecystitis) (table 2).

Funnel plots (not shown) were symmetrical for all meta-analyses indicating a low risk of publication bias.

\section{Risk Factors for Conversion of Laparoscopic Cholecystectomy to Open Surgery \\ Age}

Patient age as a risk factor for conversion to open surgery was evaluated in 27 studies $[4,8,10,11,16,24,25$, $27-30,32-37,39-46,48,52$ ]. Older age was found to be a significant risk factor in 16 studies $[8,11,25,27,30,32,34$, $36,41-46,48]$. Meta-analysis on 4 of these studies [33-35, 39] $(\mathrm{n}=2,820$, median NOS $=8$ (range $\left.7-9), \mathrm{I}^{2}=0 \%\right)$ found a pooled OR of 1.64 (95\% CI 1.22-2.19; fig. 2a). The 
Table 2. Summary finding of risk factors eligible for meta-analysis

\begin{tabular}{|c|c|c|c|c|c|c|}
\hline Risk factor & $\begin{array}{l}\text { Number of } \\
\text { patients/number } \\
\text { of studies }\end{array}$ & $\begin{array}{l}\text { Regarded as a risk } \\
\text { factor (based on } \\
\text { available evidence) }\end{array}$ & $\begin{array}{l}\text { Pooled OR } \\
(95 \% \mathrm{CI})\end{array}$ & $\begin{array}{l}\text { Quality of } \\
\text { evidence } \\
\text { (GRADE) }\end{array}$ & $\begin{array}{l}\text { NOS (median } \\
\text { for included } \\
\text { studies) }\end{array}$ & $\begin{array}{l}\text { Heterogeneity } \\
\left(\mathrm{I}^{2}\right), \%\end{array}$ \\
\hline Gender (male) & $25,778 / 9$ & Yes & $1.38(1.13-1.68)$ & Low & 8 & 49 \\
\hline BMI (high) & $20,748 / 3$ & $?$ & $1.85(0.92-3.75)$ & Very low & 8 & 74 \\
\hline Previous abdominal surgery & $23,226 / 5$ & $?$ & NA & Very low & 8 & 92 \\
\hline White blood cell count & $1,279 / 3$ & No & $0.84(0.52-1.37)$ & Low & 7 & 0 \\
\hline Gallbladder wall thickness & $1,814 / 3$ & Yes & $8.17(5.38-12.40)$ & Moderate & 7 & 0 \\
\hline
\end{tabular}

cut-off values across the studies were 60 or 65 years. Two potential studies had to be excluded because they reported age as a continuous variable $[5,42]$. The quality of evidence for age as a risk factor was low using the GRADE approach, due to the observational nature of the studies.

\section{Gender}

Gender as a risk factor for conversion was evaluated in 31 studies [4, 7-11, 16, 24, 25, 27-47]. Male gender was considered a significant risk factor for conversion in 21 studies [8-11, 16, 25, 27, 28, 30-35, 37, 38, 43-47]. Metaanalysis on 9 of these studies [7, 11, 33-35, 38, 39, 42, 47] $(\mathrm{n}=25,778$, median NOS $=8$ (range $\left.6-9), \mathrm{I}^{2}=49 \%\right)$ found a pooled OR of 1.38 (95\% CI 1.13-1.68; fig. 2b). The quality of evidence for male gender as a risk factor was low using the GRADE approach due to the observational nature of the studies. Furthermore, we observed a moderate degree of heterogeneity in the analysis.

\section{Weight/BMI}

A total of 13 studies $[4,10,11,24,27,29,30,33,34,37$, $41,44,48$ ] evaluated weight as a risk factor for conversion; however, only 6 studies $[30,33,34,37,41,48]$ found high weight to be a risk factor for conversion. Meta-analysis on 3 of these studies $[11,31,33](\mathrm{n}=20,748$, median NOS $=$ 8 (range 7-9), $\mathrm{I}^{2}=74 \%$ ) found a pooled OR of $1.85(95 \%$ CI $0.92-3.75$; fig. 2c). The quality of evidence for high weight as a risk factor was very low using the GRADE approach due to high heterogeneity.

\section{ASA-Score}

ASA-score was evaluated as a risk factor for conversion in 6 studies $[4,9,11,29,31,38]$. Of these, only 2 studies $[11,38]$ found a higher ASA-score to be a risk factor for conversion. None of the studies were eligible for inclusion in a meta-analysis.

Preoperative Risk Factor for Conversion of Cholecystectomy

\section{Diabetes Mellitus}

None of the 6 studies $[6,10,27,44,46,48]$ evaluating diabetes mellitus as a risk factor found it to be significant. None of the studies were eligible for meta-analysis.

\section{Previous Abdominal Surgery}

Previous abdominal surgery as a risk factor for conversion was evaluated in 14 studies [4, 9-11, 27, 29, 30, 33$35,41,46-48]$. In 6 studies [9-11, 27, 29, 46], previous abdominal surgery was found to be a risk factor for conversion. The 5 studies $[11,33-35,47](\mathrm{n}=23,226$, median NOS $=8$ (range 6-9)) in the meta-analysis had high heterogeneity $\left(\mathrm{I}^{2}=92 \%\right)$. As a result, the pooled OR was left out due to the possibility of an unreliable estimate (fig. $2 \mathrm{~d}$ ). We tried to include only those studies that investigated upper abdominal surgery, but this did not change the heterogeneity. The quality of evidence for previous abdominal surgery as a risk factor was very low using the GRADE approach due to the high degree of inconsistency.

\section{Body Temperature}

Three studies $[7,8,48]$ evaluated increased body temperature as a risk factor for conversion; however, none of the studies found it to be significant. None of the studies were eligible for inclusion in a meta-analysis.

\section{Acute Cholecystitis}

Acute cholecystitis as a risk factor for conversion was evaluated in 7 studies $[4,11,30,34,37,43,47]$. Four of these studies found acute cholecystitis as a significant risk factor for conversion $[4,11,34,47]$. The 3 studies $[11,34$, 47] $(\mathrm{n}=21,460$, median NOS $=8$ (range 7-9) $)$ in the meta-analysis had high heterogeneity $\left(\mathrm{I}^{2}=94 \%\right)$. However, all 3 included studies found it significantly associated with conversion. Thus, the heterogeneity was due to different estimate sizes and not due to disagreement wheth- 


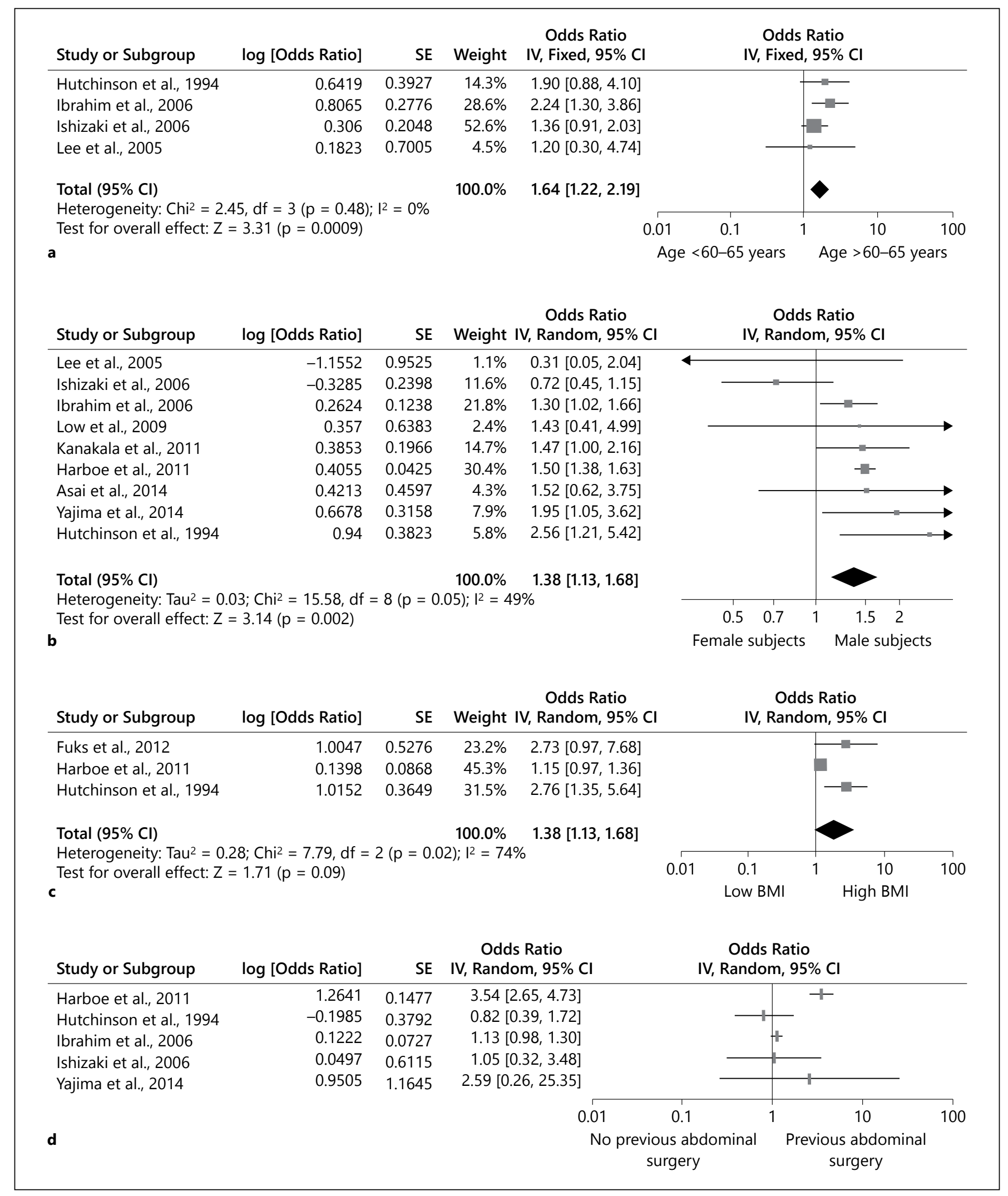

Fig. 2. a Age; b gender; c BMI; d previous abdominal surgery. 


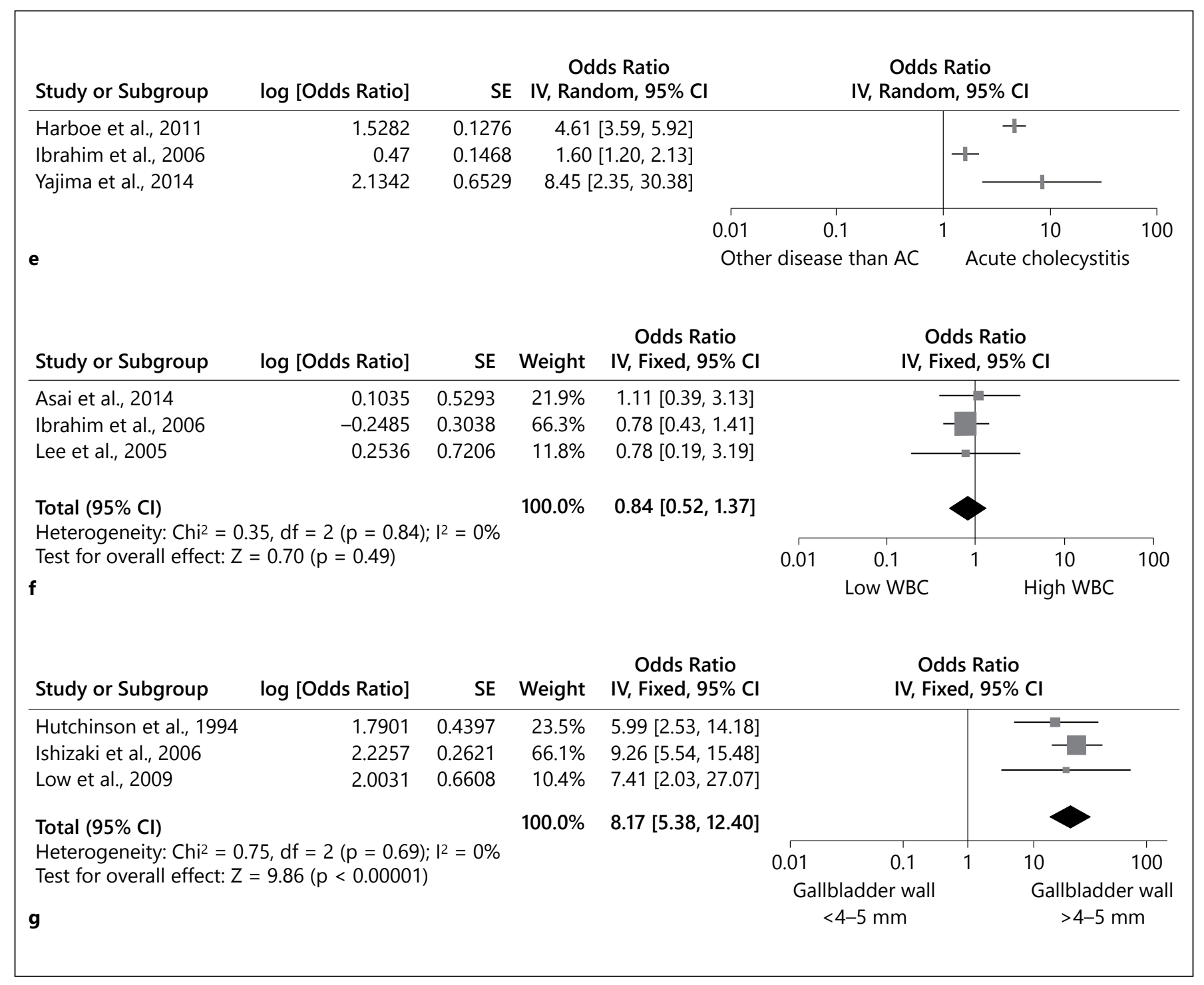

Fig. 2. e Acute cholecystitis (AC); f white blood cell (WBC) count; g gallbladder wall thickness.

er acute cholecystitis was in fact a risk factor (fig. 2e). Quality of evidence for acute cholecystitis as a risk factor was downgraded due to high inconsistency, but upgraded due to the large effect, resulting in very low quality using the GRADE approach.

\section{White Blood Cell Count}

Elevated white blood cell count as a risk factor for conversion was evaluated in 15 studies $[8-10,16,24,27$, $29,31,32,34,37,39,46,48]$, but only 5 studies [8, 9, 24, $32,46]$ found it to be a significant risk factor. Meta-analysis on 3 of these studies [7, 34, 39] ( $\mathrm{n}=1,279$, median NOS $=7$ (range $7-8), \mathrm{I}^{2}=0 \%$ ) found a pooled OR of 0.84
(95\% CI 0.52-1.37; fig. 2f). Quality of evidence for white blood cell count as a risk factor was low using the GRADE approach due to the observational nature of the studies.

\section{Preoperative Blood Tests}

A total of 12 studies [7-9, 16, 24, 27, 29, 32, 34, 37, 39, 46] evaluated various liver parameters (aspartate aminotransferase, alanine aminotransferase, alkaline phosphatase, and bilirubin) as risk factors for conversion. None of the studies were eligible for meta-analysis. Only one [27] out of 7 studies found aspartate- and alanine aminotransferase as significant risk factors for conversion. More- 
Table 3. Summary of results from the meta-analysis

\begin{tabular}{lll}
\hline Risk factors for conversion & Might be a risk factor & Not a risk factor for conversion \\
\hline Gallbladder wall $>4-5 \mathrm{~mm}$ on preoperative ultrasound & Previous abdominal surgery & Body temperature \\
Age $>60$ or 65 & BMI & Diabetes mellitus \\
Male gender & ASA-score & White blood cell count \\
Acute cholecystitis & & \\
Contracted gallbladder on ultrasound & & \\
\hline
\end{tabular}

over, one [46] out of 6 studies found elevated alkaline phosphatase as a significant risk factor for conversion. None of the 9 studies found elevated bilirubin as a risk factor for conversion. Elevated C-reactive protein was reported in 4 studies $[7,16,39,40]$ and was considered a risk factor for conversion in $3[16,39,40]$.

\section{Gallbladder Wall Thickness}

Thickness of the gallbladder wall as a risk factor for conversion was evaluated in 11 studies $[10,29,30,33$, 35-57]. A thickened gallbladder wall was considered a significant risk in 9 of these studies $[10,30,33,35-37$, 40-42]. Meta-analysis on 3 of the studies [33, 35, 42] ( $\mathrm{n}=$ $1,814$, median NOS $=7$ (range $\left.7-8), \mathrm{I}^{2}=0\right)$ found a pooled OR of 8.17 (95\% CI 5.38-12.40; fig. 2 g), suggesting that a gallbladder wall thicker than $4-5 \mathrm{~mm}$ on preoperative ultrasound was a risk factor for conversion. Quality of evidence for gallbladder wall thickness as a risk factor was considered moderate using the GRADE approach due to the size of the estimate.

\section{Medical Imaging}

A contracted gallbladder on ultrasound was evaluated only in one study [36], but in this study, it was a significant risk factor for conversion to open surgery. Pericholecystic fluid on ultrasound was a predictor in one study [48], but not in 2 other studies [40, 42]. However, when evaluated on $\mathrm{CT}$, the same measures were not risk factors [31].

\section{Discussion}

This systematic review and meta-analysis on preoperative risk factors for conversion of laparoscopic cholecystectomy to open surgery included 32 studies with 460,995 patients. We found that a gallbladder wall thicker than $4-5 \mathrm{~mm}$ or a contracted gallbladder on ultrasound, age higher than 60 or 65 , male gender, and acute cholecystitis are risk factors for conversion to open surgery. We found no association between body temperature, diabetes mellitus, or white blood cell count and conversion to open surgery. There may be an association between previous abdominal surgery, BMI or ASA-score and conversion to open surgery, but more studies are needed to verify these findings (table 3 ).

There was moderate quality of evidence to support that a thicker gallbladder wall on ultra sound was a risk factor for conversion to open surgery. Low quality of evidence supports that age over 60 or 65 and male gender are both risk factors for conversion to open surgery. Heterogeneity was classified as high for male gender but the qualitative analysis supported the findings. Therefore, we find it reasonable to conclude that male gender is a risk factor for conversion. Despite high heterogeneity, the meta-analysis pointed towards acute cholecystitis as a risk factor.

There is no obvious explanation as to why a higher age may lead to a higher conversion rate; however, the same result has also been shown for laparoscopic hysterectomy [53]. Also, the higher conversion rate in men is hard to explain. An explanation might be that men are more likely to delay seeking help $[54,55]$, and thereby present themselves with a more severe disease when they are operated. Another study [51] revealed that men have a higher risk of getting acute cholecystitis. We concluded that acute cholecystitis was a risk factor for conversion. This may be due to severe inflammation, which makes the anatomy hard to identify and therefore results in conversion $[10,48]$. The Tokyo guidelines for acute cholecystitis suggest early laparoscopic cholecystectomy for mild acute cholecystitis [56]. At the same time, they point out that moderate acute cholecystitis is associated with inflammatory changes, which make laparoscopic cholecystectomy less likely to be successful [56]. A gallbladder wall thicker than $4 \mathrm{~mm}$ is a radiological sign of acute cholecystitis [57], and inflammatory changes increase the risk of conversion. Other studies $[5,58]$ have identified an unclear anat- 
omy around the gallbladder as the most frequent reason for conversion.

According to the Cochrane Handbook [21], it is possible to consider using non-randomized trials in systematic reviews and meta-analyses if effects cannot be studied through randomized controlled trials, which is the case for studies on patient-related risk factors for conversion of laparoscopic to open cholecystectomy. However, using results from observational studies in a meta-analysis creates a weakness, as the ORs have been derived from different models including different co-variables. Thus, the included studies have adjusted for different degrees of confounding, which results in varying risk of bias in the studies. Assuming that the studies are comparable otherwise, this will be reflected in increased heterogeneity measured by the $\mathrm{I}^{2}$ test. If heterogeneity was above $75 \%$, metaanalysis was not performed, as this would increase the risk of a biased estimate. In addition, an effort was made to minimize bias by using the random effects model, which provides more conservative results than the fixed effects model by accounting for the degree of heterogeneity [59]. The strength in our studies is that we have used the best available literature on the subject by only including prospective observational and database studies. To further eliminate bias within the studies, we chose to exclude studies not performing multivariate analyses.

To avoid heterogeneity in the meta-analyses, definition of variables (risk factors) has to be alike. Two potential studies for the meta-analysis on age used continuous variables and not a cut-off point for age and were for this reason excluded. Exploring heterogeneity for acute cholecystitis and previous abdominal surgery showed that definition of the variables varied. Acute cholecystitis was defined in one study as a histopathological diagnosis [47], in another as a clinical or ultrasonic sign combined with sign of preoperative acute cholecystitis [11], or it was not described at all [34]. The meta-analysis on previous abdominal surgery included all types of abdominal surgeries, both upper and lower. To explore the heterogeneity, we tried to include only those studies that investigated the upper abdominal surgery, but this did not change the heterogeneity, excluding this as the reason for the high heterogeneity. In all analyses where heterogeneity was above $0 \%$, we used the random effects model, which provides a more conservative estimate of the pooled effect size [60].

A risk score for prediction of conversion of laparoscopic cholecystectomy has previously been created [61]; the question is if the score uses the relevant preoperative variables to predict conversion. Previous upper abdomi- nal surgery weighs heavily in their risk score, but according to our meta-analysis, this might not be a risk factor for conversion. Some of the risk factors we identified, age higher than 60 or 65 , male gender, and a gallbladder wall thicker than $4-5 \mathrm{~mm}$ on ultrasound, were also identified in the risk score for conversion [61]. Identification of these risk factors makes it possible to identify high-risk patients and thereby make relevant planning or logistic adjustments. This could be done only by having surgeons experienced at both laparoscopic and open cholecystectomy performing the operations. Moreover, by performing daytime-only surgery in these patients, more experienced surgeons may be available for consultation in case of difficulties. Another advantage is the possibility of informing patients of the higher risk for complications and a longer hospital stay and to aid the selection of patients not suited for conventional surgery, where subtotal cholecystectomy or conservative treatment may be an option.

\section{Conclusion}

We found that a thickened gallbladder wall and a contracted gallbladder on ultrasound, male gender, age above 60 or 65 , and acute cholecystitis were risk factors for conversion of laparoscopic cholecystectomy to open surgery.

\section{Disclosure Statement}

The authors declared no potential conflicts of interest with respect to the research, authorship, and/or publication of this article.

\section{References}

1 Fleisher LA, Roizen MF: Cholecystectomy, laparoscopic; in Fleisher LA, Roizen MF (eds): Essence of Anesthesia Practise. Saunders, Philadelphia, 1999, p 435.

2 Ainsworth AP, Adamsen S, Rosenberg J: Kolecystektomi I Danmark 1989-2003. Ugeskr Laeger 2005;167:2648-2650.

3 Keus F, de Jong JA, Gooszen HG, van Laarhoven CJ: Laparoscopic versus open cholecystectomy for patients with symptomatic cholecystolithiasis. Cochrane Database Syst Rev 2006;4:CD006231.

4 Al-Mulhim AA: Male gender is not a risk factor for the outcome of laparoscopic cholecystectomy: a single surgeon experience. Saudi J Gastroenterol 2008;14:73-79.

$5 \mathrm{Lim} \mathrm{KR}$, Ibrahim S, Tan NC, Lim SH, Tay KH: Risk factors for conversion to open surgery in patients with acute cholecystitis undergoing interval laparoscopic cholecystectomy. Ann Acad Med Singapore 2007;36:631-635. 
6 Alponat A, Kum CK, Koh BC, Rajnakova A, Goh PM: Predictive factors for conversion of laparoscopic cholecystectomy. World J Surg 1997;21:629-633.

7 Asai K, Watanabe M, Kusachi S, Matsukiyo H, Saito T, Kodama H, Kiribayashi T, Enomoto T, Nakamura Y, Okamoto Y, Saida Y, Nagao J: Risk factors for conversion of laparoscopic cholecystectomy to open surgery associated with the severity characteristics according to the Tokyo guidelines. Surg Today 2014;44:2300-2304.

8 Brodsky A, Matter I, Sabo E, Cohen A, Abrahamson J, Eldar S: Laparoscopic cholecystectomy for acute cholecystitis: can the need for conversion and the probability of complications be predicted? A prospective study. Surg Endosc 2000; 14:755-760

9 Kaafarani HM, Smith TS, Neumayer L, Berger DH, Depalma RG, Itani KM: Trends, outcomes, and predictors of open and conversion to open cholecystectomy in veterans health administration hospitals. Am J Surg 2010;200: 32-40.

10 Zhang WJ, Li JM, Wu GZ, Luo KL, Dong ZT: Risk factors affecting conversion in patients undergoing laparoscopic cholecystectomy. ANZ J Surg 2008;78:973-976.

11 Harboe KM, Bardram L: The quality of cholecystectomy in Denmark: outcome and risk factors for 20,307 patients from the national database. Surg Endosc 2011;25:1630-1641.

12 Wolf AS, Nijsse BA, Sokal SM, Chang Y, Berger DL: Surgical outcomes of open cholecystectomy in the laparoscopic era. Am J Surg 2009; 197:781-784.

13 Moher D, Liberati A, Tetzlaff J, Altman DG; PRISMA Group: Preferred reporting items for systematic reviews and meta-analyses: the PRISMA statement. Int J Surg 2010;8:336341.

14 PROSPERO: University of York Website (updated November 2013). http://www.crd.york. ac.uk/PROSPERO/ (accessed May 2014).

15 Higgins JPT, Deeks JJ: Chapter 7: selecting studies and collecting data; in Higgins JPT, Green S (eds): Cochrane Handbook for Systematic Reviews of Interventions, Version 5.1.0, The Cochrane Collaboration, 2011. http://www.cochrane-handbook.org.

16 Teckchandani N, Garg PK, Hadke NS, Jain SK, Kant R, Mandal AK, Bhalla P: Predictive factors for successful early laparoscopic cholecystectomy in acute cholecystitis: a prospective study. Int J Surg 2010;8:623627.

17 Greenhalgh T, Peacock R: Effectiveness and efficiency of search methods in systematic reviews of complex evidence: audit of primary sources. BMJ 2005;331:1064-1065.

18 Review Manager (RevMan) [computer program], Version 5.2. Copenhagen, The Nordic Cochrane Centre, The Cochrane Collaboration, 2008.

19 Higgins JP, Thompson SG, Deeks JJ, Altman DG: Measuring inconsistency in meta-analyses. BMJ 2003;327:557-560.
20 Wells GA, Shea B, O'Connell D, Peterson J, Welch V, Loos M, Tugwell P: The NewcastleOttawa Scale (NOS) for assessing the quality of nonrandomised studies in meta-analyses (Ottawa Hospital research institute web site) http://www.ohri.ca/programs/clinical epidemiology/oxford.asp (accessed May 2014).

21 Reeves BC, Deeks JJ, Higgins JPT, Wells GA Chapter 13: including non-randomized studies; in Higgins JPT, Green S (eds): Cochrane Handbook for Systematic Reviews of Interventions, Version 5.0.1, The Cochrane Collaboration, 2008. http://www.cochrane-handbook. org.

22 Brozek J, Oxman A, Schünemann $\mathrm{H}$ GRADEpro (for Windows) (computer program), Version 3.2, 2008.

23 Schünemann HJ, Oxman AD, Vist GE, Higgins JPT, Deeks JJ, Glasziou P, Guyatt $\mathrm{CH}$ : Chapter 12: interpreting results and drawing conclusions; in Higgins JPT, Green S (eds): Cochrane Handbook for Systematic Reviews of Interventions, Version 5.1.0, The Cochrane Collaboration, 2011. http://www.cochranehandbook.org.

24 Ancona E, Zaninotto G, Rossi M, Costantini M, Finco C, Bovolato M: The safety and feasibility of laparoscopic cholecystectomy. Ital J Gastroenterol 1992;24:320-323.

25 Ballal M, David G, Willmott S, Corless DJ, Deakin M, Slavin JP: Conversion after laparoscopic cholecystectomy in England. Surg Endosc 2009;23:2338-2344.

26 Banz V, Gsponer T, Candinas D, Güller U: Population-based analysis of 4113 patients with acute cholecystitis: defining the optimal time-point for laparoscopic cholecystectomy. Ann Surg 2011;254:964-970.

27 Botaitis S, Pitiakoudis M, Perente S, Tripsianis G, Polychronidis A, Simopoulos C: Laparoscopic cholecystectomy in acute cholecystitis: an analysis of the risk factors. S Afr J Surg 2012;50:62, 64, 68 .

28 Eldar S, Eitan A, Bickel A, Sabo E, Cohen A, Abrahamson J, Matter I: The impact of patient delay and physician delay on the outcome of laparoscopic cholecystectomy for acute cholecystitis. Am J Surg 1999;178:303307.

29 Ercan M, Bostanci EB, Teke Z, Karaman K, Dalgic T, Ulas M, Ozer I, Ozogul YB, Atalay F, Akoglu M: Predictive factors for conversion to open surgery in patients undergoing elective laparoscopic cholecystectomy. J Laparoendosc Adv Surg Tech A 2010;20:427434.

30 Fried GM, Barkun JS, Sigman HH, Joseph L, Clas D, Garzon J, Hinchey EJ, Meakins JL: Factors determining conversion to laparotomy in patients undergoing laparoscopic cholecystectomy. Am J Surg 1994;167:35-39; discussion 39-41

31 Fuks D, Mouly C, Robert B, Hajji H, Yzet T, Regimbeau JM: Acute cholecystitis: preoperative CT can help the surgeon consider conversion from laparoscopic to open cholecystectomy. Radiology 2012;263:128-138.
32 Halachmi S, DiCastro N, Matter I, Cohen A, Sabo E, Mogilner JG, Abrahamson J, Eldar S: Laparoscopic cholecystectomy for acute cholecystitis: how do fever and leucocytosis relate to conversion and complications? Eur J Surg 2000;166:136-140.

33 Hutchinson CH, Traverso LW, Lee FT: Laparoscopic cholecystectomy. Do preoperative factors predict the need to convert to open? Surg Endosc 1994;8:875-878; discussion 879880

34 Ibrahim S, Hean TK, Ho LS, Ravintharan T, Chye TN, Chee CH: Risk factors for conversion to open surgery in patients undergoing laparoscopic cholecystectomy. World J Surg 2006;30:1698-1704.

35 Ishizaki Y, Miwa K, Yoshimoto J, Sugo H, Kawasaki S: Conversion of elective laparoscopic to open cholecystectomy between 1993 and 2004. Br J Surg 2006;93:987-991.

36 Jansen S, Jorgensen J, Caplehorn J, Hunt D: Preoperative ultrasound to predict conversion in laparoscopic cholecystectomy. Surg Laparosc Endosc 1997;7:121-123.

37 Kama NA, Doganay M, Dolapci M, Reis E, Atli $\mathrm{M}$, Kologlu M: Risk factors resulting in conversion of laparoscopic cholecystectomy to open surgery. Surg Endosc 2001;15:965-968.

38 Kanakala V, Borowski DW, Pellen MG, Dronamraju SS, Woodcock SA, Seymour K, Attwood SE, Horgan LF: Risk factors in laparoscopic cholecystectomy: a multivariate analysis. Int J Surg 2011;9:318-323.

39 Lee KT, Shan YS, Wang ST, Lin PW: Verres needle decompression of distended gallbladder to facilitate laparoscopic cholecystectomy in acute cholecystitis: a prospective study. Hepatogastroenterology 2005;52:1388-1392.

40 Limbosch JM, Druart ML, Puttemans T, Melot C: Guidelines to laparoscopic management of acute cholecystitis. Acta Chir Belg 2000;100:198-204.

41 Liu CL, Fan ST, Lai EC, Lo CM, Chu KM: Factors affecting conversion of laparoscopic cholecystectomy to open surgery. Arch Surg 1996;131:98-101.

42 Low SW, Iyer SG, Chang SK, Mak KS, Lee VT, Madhavan K: Laparoscopic cholecystectomy for acute cholecystitis: safe implementation of successful strategies to reduce conversion rates. Surg Endosc 2009;23:2424-2429.

43 Russell JC, Walsh SJ, Reed-Fourquet L, Mattie A, Lynch J: Symptomatic cholelithiasis: a different disease in men? Connecticut laparoscopic cholesystectomy registry. Ann Surg 1998;227:195-200.

44 Sanabria JR, Gallinger S, Croxford R, Strasberg SM: Risk factors in elective laparoscopic cholecystectomy for conversion to open cholecystectomy. J Am Coll Surg 1994;179:696704

45 Sinha S, Hofman D, Stoker DL, Friend PJ, Poloniecki JD, Thompson MM, Holt PJ: Epidemiological study of provision of cholecystectomy in England from 2000 to 2009: retrospective analysis of hospital episode statistics. Surg Endosc 2013;27:162-175 
46 Sultan AM, El Nakeeb A, Elshehawy T, Elhemmaly M, Elhanafy E, Atef E: Risk factors for conversion during laparoscopic cholecystectomy: retrospective analysis of ten years' experience at a single tertiary referral centre. Dig Surg 2013;30:51-55.

47 Yajima H, Kanai H, Son K, Yoshida K, Yanaga $\mathrm{K}$ : Reasons and risk factors for intraoperative conversion from laparoscopic to open cholecystectomy. Surg Today 2014;44:80-83.

48 Yetkin G, Uludag M, Citgez B, Akgun I, Karakoc S: Predictive factors for conversion of laparoscopic cholecystectomy in patients with acute cholecystitis. Bratisl Lek Listy 2009;110: 688-691.

49 Eldar S, Sabo E, Nash E, Abrahamson J, Matter I: Laparoscopic cholecystectomy for acute cholecystitis: prospective trial. World J Surg 1997;21:540-545.

50 Eldar S, Sabo E, Nash E, Abrahamson J, Matter I: Laparoscopic cholecystectomy for the various types of gallbladder inflammation: a prospective trial. Surg Laparosc Endosc 1998; 8:200-207.
51 Thesbjerg SE, Harboe KM, Bardram L, Rosenberg J: Sex differences in laparoscopic cholecystectomy. Surg Endosc 2010;24:30683072.

52 Tang B, Cuschieri A: Conversions during laparoscopic cholecystectomy: risk factors and effects on patient outcome. J Gastrointest Surg 2006;10:1081-1091.

53 Twijnstra AR, Blikkendaal MD, van Zwet EW, Jansen FW: Clinical relevance of conversion rate and its evaluation in laparoscopic hysterectomy. J Minim Invasive Gynecol 2013;20:64-72.

54 Richards HM, Reid ME, Watt GC: Socioeconomic variations in responses to chest pain: qualitative study. BMJ 2002;324:1308.

55 White AK, Johnson M: Men making sense of their chest pain - niggles, doubts and denials. J Clin Nurs 2000;9:534-541.

56 Yokoe M, Takada T, Strasberg SM, Solomkin JS, Mayumi T, Gomi H, Pitt HA, Garden OJ, Kiriyama S, Hata J, Gabata T, Yoshida M, Miura F, Okamoto K, Tsuyuguchi T, Itoi T, Yamashita Y, Dervenis C, Chan AC, Lau WY,
Supe AN, Belli G, Hilvano SC, Liau KH, Kim MH, Kim SW, Ker CG; Tokyo Guidelines Revision Committee: TG13 diagnostic criteria and severity grading of acute cholecystitis. J Hepatobiliary Pancreat Sci 2013;20:35-46.

57 Gurusamy KS, Davidson BR: Gallstones. BM] 2014;348:g2669.

58 Lee HK, Han HS, Min SK, Lee JH: Sex-based analysis of the outcome of laparoscopic cholecystectomy for acute cholecystitis. Br J Surg 2005;92:463-466.

59 Burcharth J, Pommergaard HC, Rosenberg J: Performing and evaluating meta-analyses. Surgery 2015;157:189-193.

60 Deeks JJ, Higgins JPT, Altman DG: Chapter 9: analysing data and undertaking meta-analyses; in Higgins JPT, Green S (eds): Cochrane Handbook for Systematic Reviews of Interventions, Version 5.1.0, The Cochrane Collaboration, 2011. http://www.cochrane-handbook.org.

61 Kama NA, Kologlu M, Doganay M, Reis E, Atli M, Dolapci M: A risk score for conversion from laparoscopic to open cholecystectomy. Am J Surg 2001;181:520-525. 